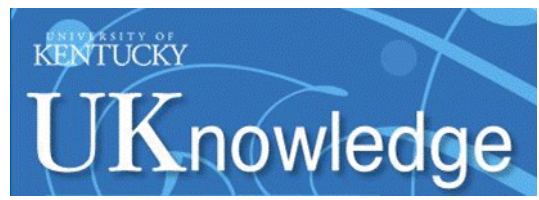

University of Kentucky

UKnowledge

\title{
$9-2018$
}

\section{Improving the Capacity Factor and Stability of Multi-MW Grid Connected PV Systems with Results from a 1MW/2MWh Battery Demonstrator}

\author{
Oluwaseun M. Akeyo \\ University of Kentucky, ochichikeyo@gmail.com \\ Vandana Rallabandi \\ University of Kentucky, vandana.rallabandi@uky.edu \\ Nicholas Jewell \\ $L G \& E$ and $K U$ \\ Dan M. Ionel \\ University of Kentucky, dan.ionel@uky.edu
}

Follow this and additional works at: https://uknowledge.uky.edu/peik_facpub

Part of the Power and Energy Commons

Right click to open a feedback form in a new tab to let us know how this document benefits you.

\section{Repository Citation}

Akeyo, Oluwaseun M.; Rallabandi, Vandana; Jewell, Nicholas; and Ionel, Dan M., "Improving the Capacity Factor and Stability of Multi-MW Grid Connected PV Systems with Results from a 1MW/2MWh Battery Demonstrator" (2018). Power and Energy Institute of Kentucky Faculty Publications. 29.

https://uknowledge.uky.edu/peik_facpub/29

This Conference Proceeding is brought to you for free and open access by the Power and Energy Institute of Kentucky at UKnowledge. It has been accepted for inclusion in Power and Energy Institute of Kentucky Faculty Publications by an authorized administrator of UKnowledge. For more information, please contact UKnowledge@lsv.uky.edu. 


\title{
Improving the Capacity Factor and Stability of Multi-MW Grid Connected PV Systems with Results from a $1 \mathrm{MW} / 2 \mathrm{MWh}$ Battery Demonstrator
}

\author{
Digital Object Identifier (DOI) \\ https://doi.org/10.1109/ECCE.2018.8558253
}

\section{Notes/Citation Information}

Published in 2018 IEEE Energy Conversion Congress and Exposition (ECCE).

(C) 2018 IEEE Copyright Notice. "Personal use of this material is permitted. Permission from IEEE must be obtained for all other uses, in any current or future media, including reprinting/republishing this material for advertising or promotional purposes, creating new collective works, for resale or redistribution to servers or lists, or reuse of any copyrighted component of this work in other works."

The document available for download is the authors' manuscript version that is accepted for publication. The final published version is copyrighted by IEEE and available as: O. M. Akeyo, V. Rallabandi, N. Jewell and D. M. Ionel, "Improving the Capacity Factor and Stability of Multi-MW Grid Connected PV Systems with Results from a 1MW/2MWh Battery Demonstrator," 2018 IEEE Energy Conversion Congress and Exposition (ECCE), Portland, OR, 2018, pp. 2504-2509. doi: 10.1109/ECCE.2018.8558253 


\section{Improving the Capacity Factor and Stability of Multi-MW Grid Connected PV Systems with Results from a 1MW/2MWh Battery Demonstrator}

\author{
Oluwaseun Akeyo \\ SPARK Lab, ECE Dept. \\ University of Kentucky \\ Lexington, KY, USA \\ m.akeyo@uky.edu
}

\author{
Vandana Rallabandi \\ SPARK Lab, ECE Dept. \\ University of Kentucky \\ Lexington, KY, USA \\ vandana.rallabandi@uky.edu
}

\author{
Nicholas Jewell \\ $L G \& E$ and $K U$ \\ PPL Companies \\ Louisville, KY, USA \\ nicholas.jewell@lge-ku.com
}

\author{
Dan M. Ionel \\ SPARK Lab, ECE Dept. \\ University of Kentucky \\ Lexington, KY, USA \\ dan.ionel@uky.edu
}

\begin{abstract}
Conventional PV systems integrated with a battery connect the array and the energy storage unit to a dc-link through individual dc-dc converters for maximum power point tracking (MPPT) and battery charge control. This paper proposes a new system configuration, which connects the PV array and battery unit to the dc-link of the system inverter via a single dc-dc converter capable of simultaneously operating as a charge controller and MPPT device. This dc-dc converter is controlled such that it charges/discharges the battery with the amount of power required to maintain the PV array at its MPPT reference voltage. The proposed system ensures that the PV array operates at its MPP for all irradiance conditions, therefore increasing the PV system capacity factor as well as ensuring MPPT stability for all irradiance conditions. Also, this configuration may also be adopted for PV power smoothing, where the curtailed power may be used to smooth the PV inverter output without sacrificing battery state of charge (SOC). The behavior of the proposed system is studied and simulated in PSCAD $^{T M} /$ EMTDC $^{T M}$. The computations are compared with experimental data retrieved from the LG\&E and KU E.W. Brown universal solar facility, which houses a 10MW(ac) PV farm and a 1MW/2MWh battery energy storage system (BESS). The results show that for the examples considered, and allowing curtailment adapted to the current power ratings of the system, an increase in the capacity factor of up to $20 \%$ is possible.

Index Terms-PV, battery, MPPT, grid connected inverter, dc-
\end{abstract} dc converter, charge controller, energy storage.

\section{INTRODUCTION}

The photovoltaic (PV) energy installations are fast growing both for residential applications, as well as for utility sized power plants [1]. Solar PV generation is intermittent in nature, and much of the associated research focuses on employing battery energy storage systems (BESS) in order to mitigate this inherent limitation. Power electronic devices play major roles in PV and BESS integration, fulfilling multiple functions including ac-dc transformation, PV maximum power point tracking (MPPT), and battery charge control [2].

Analyses have shown substantial benefits of single-stage grid connected PV systems over two-stage PV systems, some of which includes: lower cost, smaller system size, and higher efficiency [3], [4]. Configurations with PV systems incorporating BESS typically introduce two additional dc-dc converters, which increase the system complexity and reduce its overall efficiency due to losses in the supplementary components [5][8]. These configurations interface the battery pack and PV array to the inverter dc-link via individual dc-dc converters (Fig. 1a). For such topologies, the PV array dc-dc converter ensures that the PV array voltage corresponds to its MPP and the battery dc-dc converter serves as a charge controller that regulates the inverter dc link voltage [9]-[11].

Other configurations for battery integrated PV systems using a single dc-dc converter have been presented in literature. In [12], the battery is directly connected to the dc bus of a two-stage converter, which ensures simplicity, but leads to additional losses in the dc-dc converter when the battery is not operational, further affecting the battery over-voltage protection and the effectiveness of the control for the battery charge and discharge operations. Recent research has proposed connecting the BESS to the grid through its own inverter (Fig. $1 b)$. This configuration allows the PV and the BESS to operate as independent systems [13], [14]. However, the configuration is less efficient, since power needs to flow through two acdc converters when charging the battery with the PV power. Also, the PV dc-ac converter needs to have similar ratings as the PV array in order to maintain it at MPP for all irradiance conditions when using an independent BESS, which leads to a substantial reduction in the utilization factor of such ac-dc converter installation.

\section{Proposed System Confirguration}

The multi-MW PV system configuration proposed in this paper is divided into multiple modular sections, where each includes a PV array, battery unit, bidirectional dc-dc converter, two level grid connected inverter and transformer (Fig. 1c). The utilized dc-dc converter operates simultaneously as a charge and as an MPPT controller by varying the charge/discharge power of the battery pack in order to maintain the PV array at the voltage corresponding to its MPP. This proposed configuration allows the battery integrated PV system to operate as a single stage PV system during periods when the battery is not operational. Also, the proposed configuration 


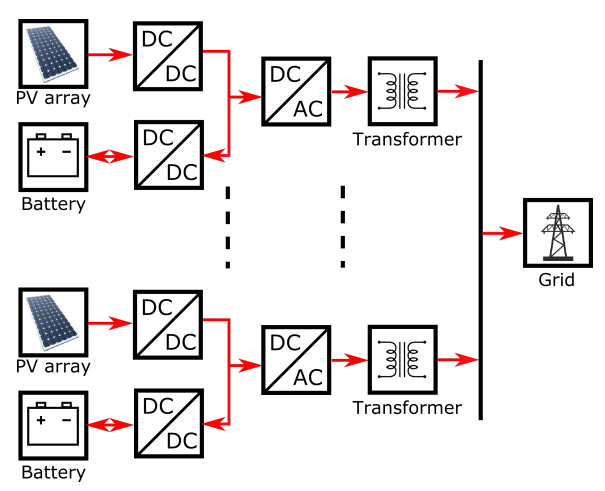

(a)

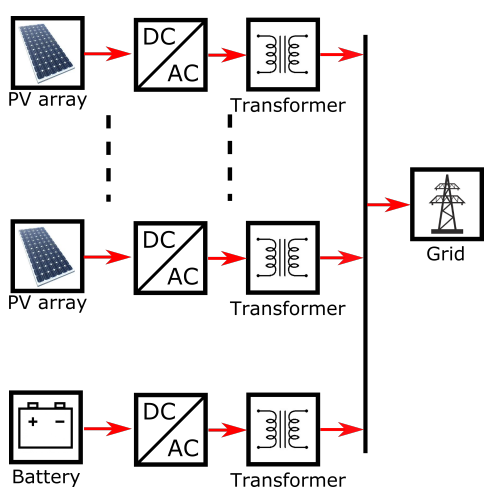

(b)

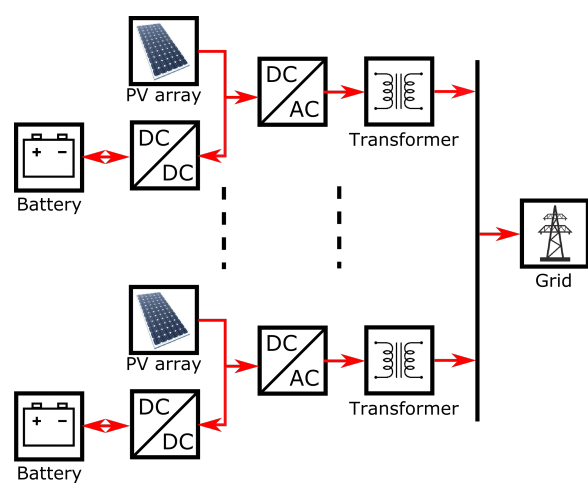

(c)

Fig. 1. Example configurations of multi-MW PV system with BESS: (a) Conventional system with multiple dc-dc converters for MPPT and charge control, (b) field implemented system with BESS connected to the grid via independent inverter, (c) proposed system with single dc-dc converter for MPPT and charge control. These systems may also be connected to the grid without a transformer.

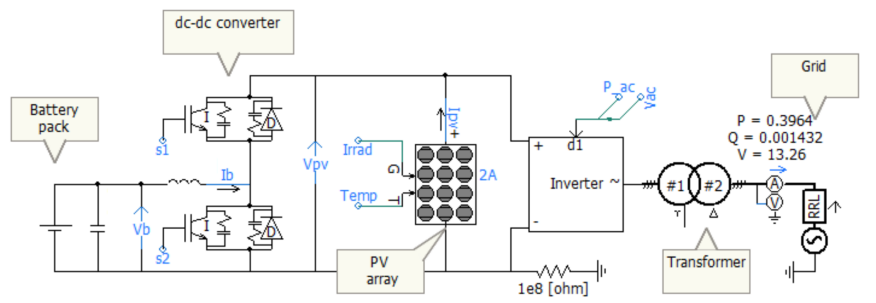

Fig. 2. The power circuit diagram in the $\mathrm{PSCAD}^{T M} / \mathrm{EMTDC}^{T M}$ software environment for a single unit of the proposed system in Fig. 1c, where a constant voltage source is used to represent the grid.

TABLE I

MAIN SPECIFICATION FOR 10MW PV POWER Plant

\begin{tabular}{lrr} 
& Experimental & Proposed \\
\hline Rated power (MW/section) & 1.00 & 1.00 \\
Clear day capacity factor (\%) & 38.91 & 44.50 \\
Clear day PV energy (MWh/section) & 9.34 & 10.68 \\
PV smoothing Battery usage (MWh/section) & 0.40 & -0.74 \\
Curtailment MPPT & unstable & stable \\
Max. PV array dc power & inverter rating & PV rating \\
Battery charge efficiency & $\eta_{i n v} \times \eta_{i n v}$ & $\eta_{d c d c}$ \\
\hline
\end{tabular}

can be used to improve the overall system stability of the PV system by constantly maintaining the PV array at its MPP reference voltage during periods of excess irradiance.

The proposed system is compared with the LG\&E and KU E.W. Brown universal solar facility system, wherein the PV array and BESS are connected to the grid through individual inverters (Fig. 1b). A study on constant power production and PV output power smoothing using BESS is presented for both system configurations. In addition to PV power smoothing and constant power generation, this system may also be configured to perform other ancillary functions including frequency and voltage regulation, and reactive power compensation. The system and its controls are analyzed and simulated on an accelerated time scale using the PSCAD ${ }^{T M} / \mathrm{EMTDC}^{T M}$ software (Fig. 2).

\section{SyStem MODELING}

Battery energy storage system(s) are expected to play a significant role in the integration of renewable energy sources into the future electric grid. Typical field implementation of Multi-MW PV systems exists as single stage systems, which includes multiple sections of PV arrays interfaced with the grid via a dc-ac converter capable of performing MPPT. The proposed configuration may be used to enhance the operation of this existing systems by connecting a battery pack via a bidirectional dc-dc converter to the existing inverter dc link. Depending on the power and energy rating of the integrated BESS, the proposed system may be used to perform operations such as, PV output power smoothing, PV constant power production and peak shifting.

\section{A. PV array}

The field implemented PV system consist of ten PV arrays, each made up of 19 Jinko JKM315P-72 PV modules connected in series and an average of 236 module strings in parallel. An equivalent PV array was modeled in $\mathrm{PSCAD}^{T M} / \mathrm{EMTDC}^{T M}$ with each $315 \mathrm{~W}$ PV panel rated at $46.75 \mathrm{~V}$ open circuit voltage and $9.02 \mathrm{~A}$ short circuit current. The equivalent circuit of the PV cell was modeled based on

$$
i=i_{g}-i_{o}\left[\exp \left(\frac{v+i R_{s r}}{n \mathrm{~K} T_{c} / q}\right)-1\right]-\left(\frac{v+i R_{s r}}{R_{s h}}\right),
$$

where, $i$ represents the cell output current; $i_{g}$, the component of cell current due to photons; $i_{o}$, the saturation current; K, the Boltzmann constant $\left(\mathrm{K}=1.3810^{-23} \mathrm{j} / K\right)$; $q$, the electron charge $\left(\mathrm{q}=1.6 \times 10^{-19} \mathrm{C}\right) ; \mathrm{v}$, the output voltage; $T_{c}$, the cell temperature; $R_{s h}$, the shunt resistance and $R_{s r}$, the series resistance.

\section{B. Battery}

The field implemented energy storage site consists of two shipping containers (Fig. 3) with multiple Li-ion LG chem battery modules, each rated for $51.8 \mathrm{~V} / 126 \mathrm{Ah}$ connected in series and parallel to make up a $1 \mathrm{MW} / 2 \mathrm{MWh}$ battery pack 


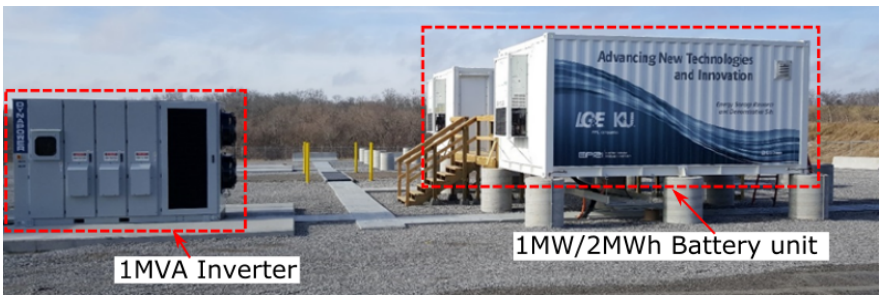

(a)

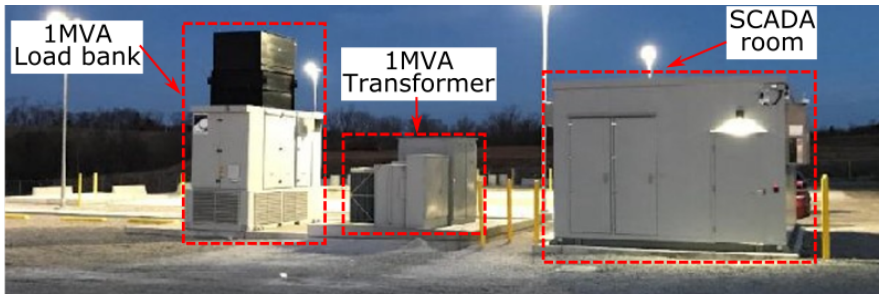

(b)

Fig. 3. The battery energy storage system (BESS) setup at E.W Brown LG\&E KU facility rated $1 \mathrm{MW} / 2 \mathrm{MWh}$. (a) Two parallel battery container units directly connected to the dc link of the bidirectional dc-ac converter, (b) SCADA room for high resolution data management and system control. The experimental facility may be operated in islanded mode with the 1MVA load bank connected to the secondary side of the transformer.

connected to the grid through an independent inverter. The proposed system was modeled with a $0.35 \mathrm{kV}$ nominal voltage battery, which was developed as a non-linear voltage source with open circuit voltage, $E$, given as:

$$
E=E_{0}-K \cdot \frac{1}{S O C}+A \cdot e^{-B \cdot Q(1-S O C)},
$$

where $E_{0}$ is battery constant voltage, $K$ is polarization voltage, $Q$ is battery capacity, $A$ is exponential zone amplitude, $B$ is exponential zone time constant inverse and $S O C$ is the battery state of charge.

\section{Bidirectional $d c-d c$ converter}

The bidirectional dc-dc converter (Buck/Boost) employed for the proposed configuration consists of two IGBT switches, inductor and capacitor (Fig. 4). Depending on the IGBT switches input signal, this converter is capable operating as either a boost or buck converter. In conventional single stage PV systems, the PV array terminal voltage deviates from its MPP and tends toward open circuit voltage when the inverter reference power is less than the array available power or short circuit when the inverter reference power is higher than the array available power.

The proposed configuration ensures MPPT stability by maintaining the PV array terminal voltage at its MPP reference when there is a mismatch between the PV array and inverter reference power (Fig. 5). Switch $S_{1}$ is operated to charge the battery (buck mode) with the excess power required to maintain the PV array terminal voltage at its MPP when its terminal voltage is greater than its MPP reference, and switch $S_{2}$ is operated to discharge the battery (boost mode) of the deficit power when the array terminal voltage is less than

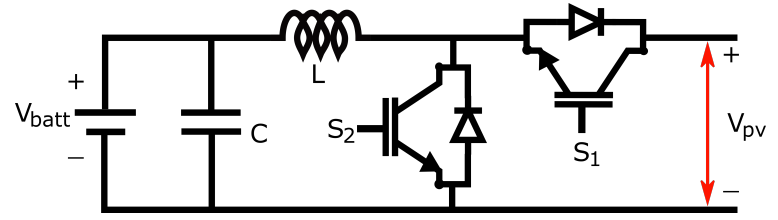

Fig. 4. The battery unit connected to the PV array and inverter dc-link through a bidirectional converter, where switch $S_{1}$ and $S_{2}$ are used to regulate the battery charge and discharge current, respectively.

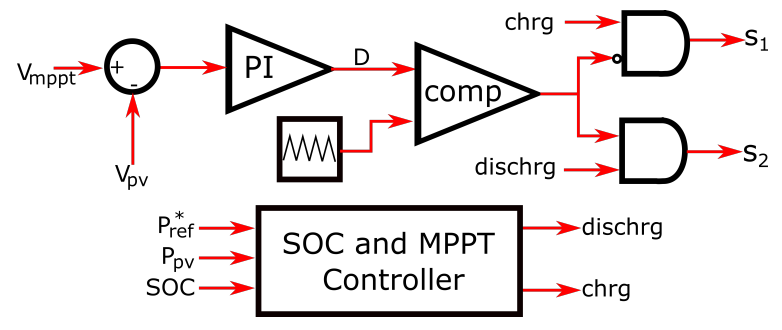

Fig. 5. The BESS converter control so that battery supplies or absorbs the amount of power required to maintain the $\mathrm{PV}$ array voltage $\left(V_{p v}\right)$ at the voltage corresponding to its MPP $\left(V_{M P P T}\right)$.

the its MPP reference. The converter current in charge and discharge mode is given as:

$$
\begin{gathered}
i_{c h r g}=\frac{\left(i_{p v}-i_{i n v}\right)}{\left(V_{M P P T}-V_{p v}\right)\left(K_{p s}+\frac{K_{i s}}{s}\right)}, \\
i_{\text {dischrg }}=\frac{\left(i_{i n v}-i_{p v}\right)}{\left[1-\left(V_{M P P T}-V_{p v}\right)\left(K_{p s}+\frac{K_{i s}}{s}\right)\right]},
\end{gathered}
$$

where $i_{c h r g}$ and $i_{\text {dischrg }}$ are the battery charging and discharge currents, respectively; $V_{M P P T}$, the reference MPP voltage; $V_{p v}$, PV array terminal voltage; $i_{i n v}$, inverter input current; $K_{p s}$ and $K_{i s}$, PI controller constants. The converter control interrupts battery power flow when the battery state of charge (SOC) is not within operational limits.

\section{Voltage controlled dc-ac converter}

The experimental setup interfaces the PV array and the battery pack to the grid via individual dc-ac converters. The battery dc-ac converter serves as a charge controller for the battery, which may be controlled with respect to the grid requirement or PV variation. This independent battery setup is capable of performing ancillary function such as: PV power smoothing, frequency regulation, peak shaving, and voltage regulation. The PV inverter is used to maintain the PV array dc voltage at its MPP by varying its ac output power.

The proposed PV system adopts a two level inverter, which is a widely available technology that is relatively low-priced with straightforward control and has been demonstrated to be reliable for small inverters below 1MW. The control block diagram for the voltage oriented control inverter proposed for each section is illustrated in Fig.6. The inverter active $\left(P_{r e f}^{*}\right)$ and reactive $\left(Q_{r e f}^{*}\right)$ reference power, may be controlled in different modes such as constant power, PV smoothing 


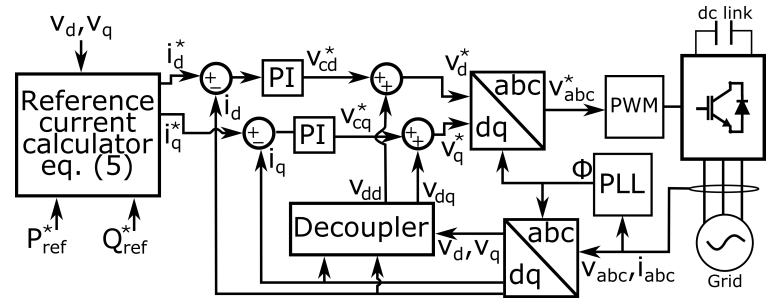

Fig. 6. The voltage source inverter control. The proposed system uses a decoupled control, which allows independent control of the system real and reactive power output. The reference active power, $P_{r e f}^{*}$ may be controlled for PV power smoothing, constant power generation and MPPT.

and MPPT to generate corresponding decoupled $\mathrm{d}-\mathrm{q}$ reference frames current components using:

$$
i_{d}^{*}=\frac{2}{3} \frac{P_{r e f}^{*}}{v_{d}}, \quad i_{q}^{*}=\frac{2}{3} \frac{Q_{r e f}^{*}}{v_{q}},
$$

where $v_{d}, v_{q}$ and $i_{d}^{*}, i_{q}^{*}$, are d-q reference frame voltage and currents, respectively. For simplicity, the reference reactive power of the system is maintained at zero. When the battery SOC is above maximum or below minimum, the PV inverter is operated in MPPT mode, which ensures the PV system terminal voltage is equal to its reference value.

$$
P_{r e f}^{M P P T}=\left(V_{M P P T}-V_{p v}\right)\left(K_{p i}+\frac{K_{i i}}{s}\right),
$$

where $P_{r e f}^{M P P T}$ is the real reference power at MPPT; and $K_{p i}$ and $K_{i i}$ are the PI controller constants.

\section{SMOOTHING PV POWER}

Battery energy storage systems may be employed on a cloudy day, to smooth the PV output power variation, in order to improve the delivered power quality, meet grid ramp rate limitations and limit potential frequency deviations. In the case of multi-MW PV systems, sudden changes in the output power due to cloud movement can potentially induce severe voltage fluctuations leading to grid stability issues [15]. Utility companies with high renewable energy penetration often limit their maximum allowable ramp rate to $10 \%$ per minute, based on system's rated capacity [16]. Different methods of curtailing the PV system real power output ramp rate through modified MPPT algorithms have been proposed [17], [18]. These methods lead to increased computational burdens, reduction in energy produced by the PV system and also require accurate weather forecasting devices. For this approach, the reference real power output of the PV inverter $\left(P_{r e f}^{M A}\right)$ is computed using a moving average (MA) technique to determine the sample mean of the saturated PV output estimated as:

$$
P_{r e f}^{M A}(t)=\frac{P_{d c}(t)+P_{d c}(t-1)+\ldots+P_{d c}(t-\Delta+1)}{\Delta},
$$
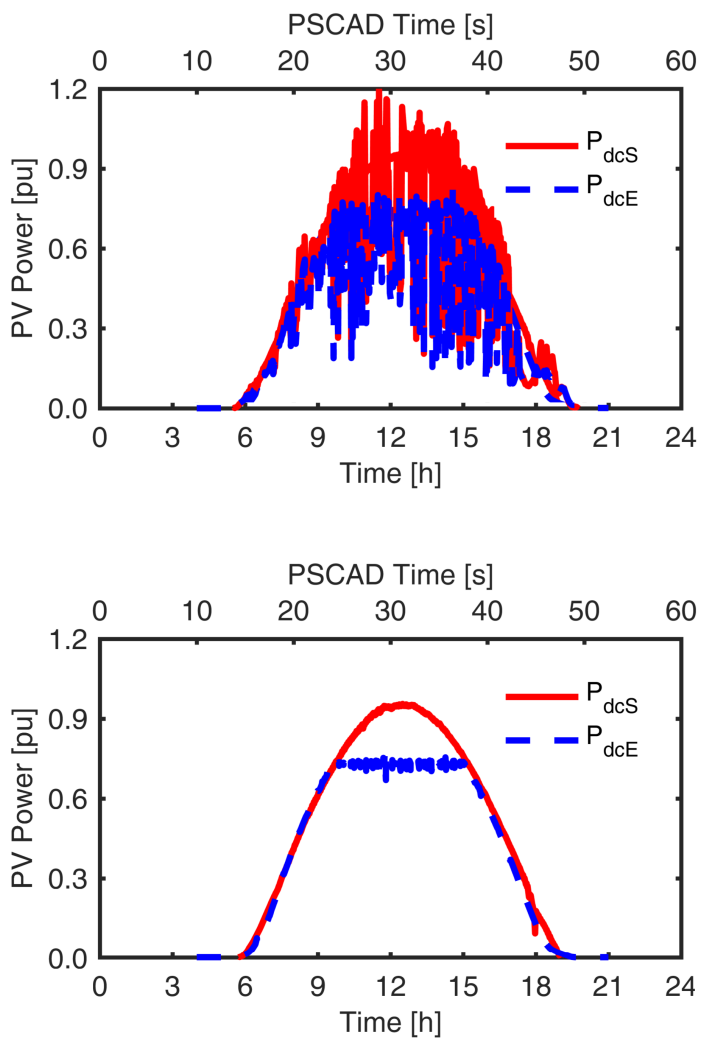

Fig. 7. An example PV array dc output power for the proposed $\left(P_{d c S}\right)$ and experimental $\left(P_{d c E}\right)$ system setup on a cloudy and clear day. The proposed configuration is able to increase the overall capacity factor by absorbing all the dc power available from its PV array during power curtailment. $P_{\text {base }}=1.4 \mathrm{MW}$.

where $P_{r e f}^{M A}$ is the smooth PV power output; $P_{d c}$, the PV system dc output power; $\mathrm{t}$, the time and $\Delta$, the number of considered points. For this study, the proposed system operation over a cloudy day was analyzed using irradiance data retrieved from two weather stations on the LG\&E and KU 10MW universal solar facility and simulated on a $\mathrm{PSCAD}^{T M} / \mathrm{EMTDC}^{T M}$ accelerated time scale. The moving average sample data was computed over 1000s, which reduced the maximum PV system ramp rate from $56.31 \% / \mathrm{min}$ to $4.15 \% / \mathrm{min}$ maximum (Fig. 8).

The BESS is controlled to supply the power difference between the available PV power and the computed moving average power of the PV system (Fig. 9). The field implemented $1 \mathrm{MW} / 2 \mathrm{MWh}$ BESS requires 0.40MWh energy in order to smooth the output power of the PV system while the proposed configuration smooths the PV output power, maintains the PV array at its MPP and provides additional storage energy of $0.74 \mathrm{MWh}$ to the battery which may be supplied to the grid at later hours.

\section{Constant Power Generation}

In the field implemented system considered for this study, the PV system dc to ac rating is approximately 1.4:1. Hence, the PV array is forced to deviate from its MPP to supply the rated ac power when the available solar power is excess, 


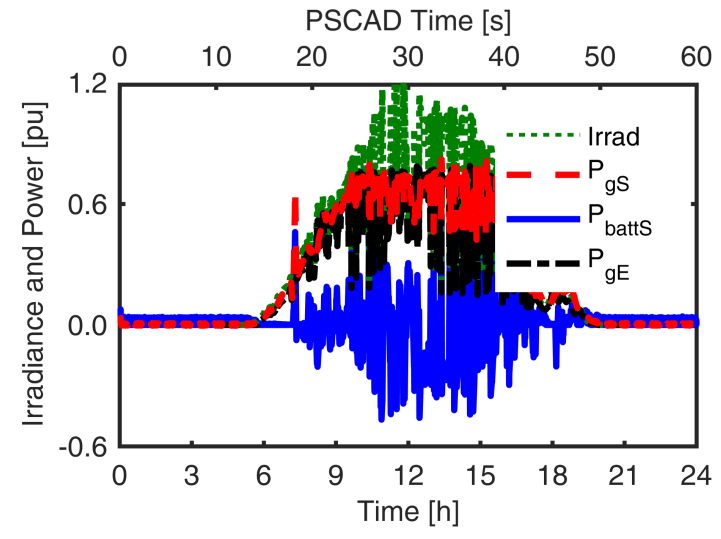

Fig. 8. PV output power smoothing over a cloudy day; Per unit ac output power and experimental irradiance data $\left(\right.$ irrad) for the proposed $\left(P_{g S}\right)$ and field implemented systems $\left(P_{g E}\right)$, where $P_{b a t t E}$ represents the battery dc output power. irrad $_{\text {base }}=1000 \mathrm{~W} / \mathrm{m}^{2}$ and $P_{\text {base }}=1.4 \mathrm{MW}$.

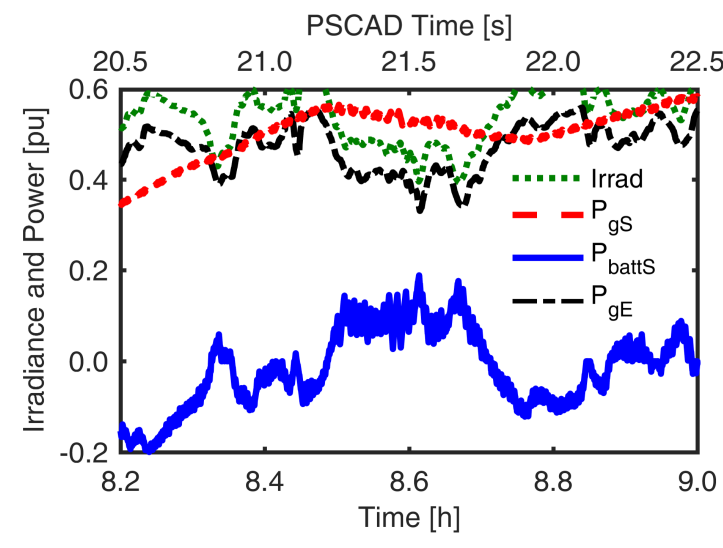

Fig. 9. A zoomed representation of cloudy day power variation for experimental and simulated results. Battery charges and discharge at high frequency in order to reduce PV ramp rate while maintaining PV array voltage at MPP reference.

which might potentially lead to an unstable MPPT operation. The proposed configuration uses the BESS to absorb this surplus power, allowing the PV array to operate at MPP during periods of excess irradiance (Fig. 7). This stored energy may be supplied back to the grid to maintain the PV output power at the rated value during periods of lower irradiance.

The performance of the proposed and field implemented systems were compared via simulation studies, where the irradiance data used for simulation was calculated as an average from two weather stations on the LG\&E and KU 10MW universal solar facility on a clear day and the PV cell temperature estimated as a function of the ambient temperature. The field implemented system starts operating at constant power mode when the solar irradiance is greater than $714.28 \mathrm{~W} / \mathrm{m}^{2}$, making its $\mathrm{PV}$ array voltage deviate towards open circuit (Fig. 10) and to the right of its MPP on a powervoltage (P-V) curve, which is unstable for MPPT [15]. The proposed system addresses this limitation by maintaining the PV array at its MPP for all conditions of irradiance. In this approach, the PV system supplies constant power for a longer

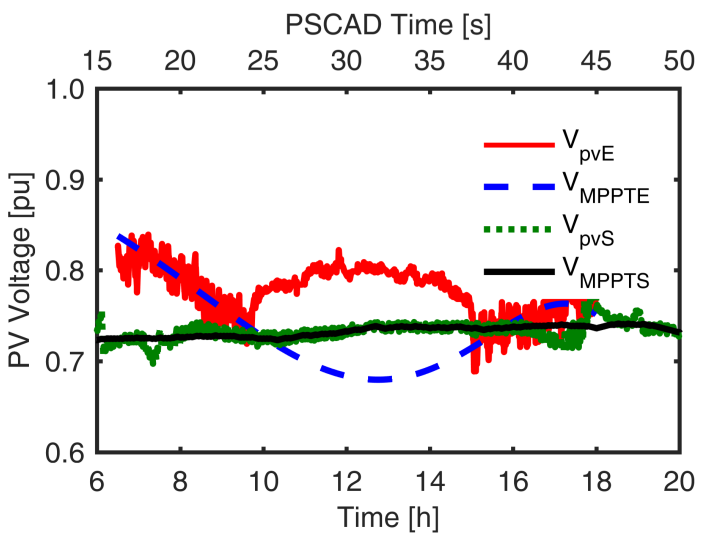

Fig. 10. The PV array terminal voltage and MPPT reference, illustrating MPPT stability of proposed system during power curtailment. Where $V_{p v E}$, $V_{M P P T E}, V_{p v S}$, and $V_{M P P T S}$ represents the $\mathrm{PV}$ array voltage and MPPT reference for the experimental and proposed setup at $V_{b a s e}=0.89 \mathrm{kV}$, respectively.

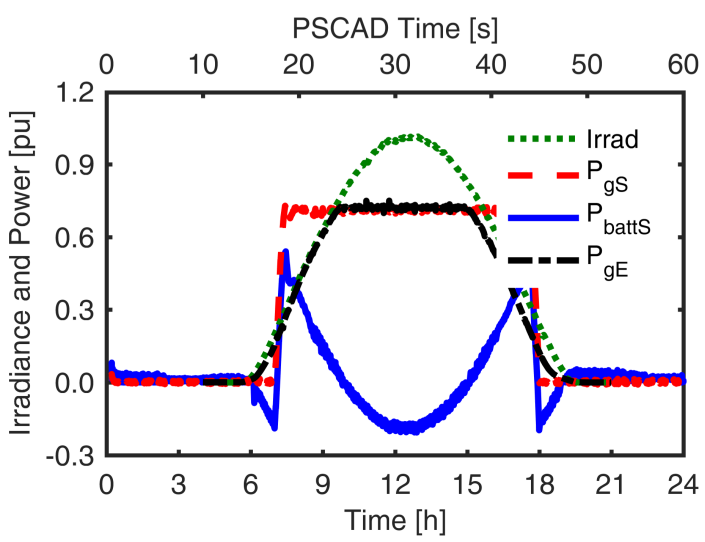

Fig. 11. The system ac output power and experimental irradiance data (irrad) for the proposed $\left(P_{g S}\right)$ and field implemented systems $\left(P_{g E}\right)$. The battery dc power, $P_{b a t t S}$, is regulated such that the excess power absorbed during curtailment is supplied back to the grid to extend the rated power production duration. The irrad $_{\text {base }}=1000 \mathrm{~W} / \mathrm{m}^{2}, P_{\text {base }}=1.4 \mathrm{MW}$.

period of time while ensuring the system ramp rate does not exceed $\pm 10 \% / \mathrm{min}$ (Fig. 11).

The proposed configuration provides substantial increase in the system capacity factor and inverter utilization factor, by extending the duration of time, which the PV system supplies its rated power. The constant power operation condition is described by:

$$
\begin{gathered}
\int_{0}^{T} P_{d c S} d t=\int_{0}^{T} P_{g E} d t \\
P_{r}=\max \left|\left(P_{g S}-P_{d c S}\right)\right|, \\
E_{r}=\int_{0}^{T}\left(P_{d c S}-P_{d c E}\right) d t
\end{gathered}
$$

where $P_{d c S}$ and $P_{d c E}$, are the available PV array dc power for the proposed and field implemented system; $P_{g E}$, is the 
inverter output power to the grid; $T$, is the time period considered; $E_{r}$ and $P_{r}$, are the battery rated energy and power, respectively. Over the clear day analyzed in this study, the proposed configuration increased the PV system capacity factor by approximately $13.3 \%$ with the capacity factor $(C F)$ defined as:

$$
C F(\%)=\frac{\int_{0}^{T} P_{g} d t}{P \cdot T} \cdot 100,
$$

where $P$ is the PV system rated output power; and $\mathrm{P}_{g}$ is the ac power output for the concerned system. The field implemented and proposed PV systems produced 9.34MWh and 10.68MWh per section, respectively. This potential $13.3 \%$ increase in the PV system output energy, hence capacity factor, can be achieved with a $0.76 \mathrm{MW} / 1.25 \mathrm{MWh}$ battery energy storage system connected to each section.

As a design exercise, following the experimental study previously presented, the available $1 \mathrm{MW} / 2 \mathrm{MWh}$ battery unit with a larger PV array of $1.54 \mathrm{MW}$ on the best weather condition is capable of producing $11.75 \mathrm{MWh}$ with the $1 \mathrm{MW}$ inverter. Hence, increasing the system capacity factor by $20.4 \%$.

\section{CONCLUSION}

This paper proposes a method for integrating BESS into multi-MW PV systems through the use of a bidirectional dcdc converter, capable of simultaneously operating as a charge controller and MPPT device, and employs distributed energy storage for PV arrays. Advantages include increased total energy output of the PV system, improved control of the PV system dc-link voltage during power curtailment, and higher system efficiency. Furthermore, the new approach provides a relatively low cost for battery integrated PV systems without the need for an additional dc-dc converter for MPPT optimal control.

The detailed technical benefits of the proposed configuration with respect to PV output power smoothing and constant power generation were illustrated through $\mathrm{PSCAD}^{T M} / \mathrm{EMTDC}^{T M}$ simulations of two case studies with irradiance variation for a clear and cloudy day. Ongoing research includes studies for system control variations and potential additional benefits, such as frequency regulation, VAR compensation, voltage support, black start and islanded operation. In order to validate the capabilities and effectiveness of the proposed system and controls, its simulated performance was compared with computed and experimental data from the LG\&E and KU E.W. Brown universal solar facility, which houses a 10MW PV farm and a 1MW/2MWh BESS. The results show that for the examples considered, and allowing curtailment adapted to the current power ratings of the system, an increase in the capacity factor of up to $20 \%$ is possible.

\section{ACKNOWLEDGMENT}

The authors thank Dr. David Link of LG\&E and KU and the team of technical experts from Nayak Corp. for their technical advice and contributions. The support of University of Kentucky, the L. Stanley Pigman endowment, Power and
Energy Institute of Kentucky (PEIK), and of LG\&E and KU is gratefully acknowledged.

\section{REFERENCES}

[1] F. Blaabjerg and D. M. Ionel, "Renewable energy devices and systems state-of-the-art technology, research and development, challenges and future trends," Electric Power Components and Systems, vol. 43, no. 12, pp. 1319-1328, 2015.

[2] F. Blaabjerg and D. M. Ionel, Renewable Energy Devices and Systems with Simulations in MATLAB and ANSYS. CRC Press, 2017.

[3] T. F. Wu, C. H. Chang, L. C. Lin, and C. L. Kuo, "Power loss comparison of single- and two-stage grid-connected photovoltaic systems," vol. 26 , no. 2, June 2011, pp. 707-715.

[4] Y. Zhu, J. Yao, and D. Wu, "Comparative study of two stages and single stage topologies for grid-tie photovoltaic generation by PSCAD/EMTDC," in 2011 International Conference on Advanced Power System Automation and Protection, vol. 2, Oct 2011, pp. 13041309.

[5] O. M. Akeyo, V. Rallabandi, and D. M. Ionel, "Multi-MW solar PV pumping system with capacity modulation and battery voltage support," in 2017 IEEE 6th International Conference on Renewable Energy Research and Applications (ICRERA), Nov 2017, pp. 423-428.

[6] A. Merabet, K. T. Ahmed, H. Ibrahim, R. Beguenane, and A. M. Y. M. Ghias, "Energy management and control system for laboratory scale microgrid based wind-pv-battery," IEEE Transactions on Sustainable Energy, vol. 8, no. 1, pp. 145-154, Jan 2017.

[7] J. Sachs and O. Sawodny, "A two-stage model predictive control strategy for economic diesel-PV-battery island microgrid operation in rural areas," IEEE Transactions on Sustainable Energy, vol. 7, no. 3, pp. 903-913, July 2016.

[8] V. Karthikeyan and R. Gupta, "Varying phase angle control in isolated bidirectional dc 8211;DC converter for integrating battery storage and solar PV system in standalone mode," IET Power Electronics, vol. 10, no. 4, pp. 471-479, 2017.

[9] M. O. Badawy and Y. Sozer, "Power flow management of a grid tied PV-battery system for electric vehicles charging," IEEE Transactions on Industry Applications, vol. 53, no. 2, pp. 1347-1357, March 2017.

[10] N. Saxena, I. Hussain, B. Singh, and A. L. Vyas, "Implementation of a grid-integrated PV-battery system for residential and electrical vehicle applications," IEEE Transactions on Industrial Electronics, vol. 65, no. 8, pp. 6592-6601, Aug 2018.

[11] P. Satapathy, S. Dhar, and P. K. Dash, "Stability improvement of PVBESS diesel generator-based microgrid with a new modified harmony search-based hybrid firefly algorithm," IET Renewable Power Generation, vol. 11, no. 5, pp. 566-577, 2017.

[12] M. Rezkallah, A. Hamadi, A. Chandra, and B. Singh, "Real-time HIL implementation of sliding mode control for standalone system based on pv array without using dumpload," IEEE Transactions on Sustainable Energy, vol. 6, no. 4, pp. 1389-1398, Oct 2015.

[13] V. Rallabandi, O. M. Akeyo, and D. M. Ionel, "Modeling of a multimegawatt grid connected PV system with integrated batteries," in 2016 IEEE International Conference on Renewable Energy Research and Applications (ICRERA), Nov, pp. 1146-1151.

[14] H. Mahmood, D. Michaelson, and J. Jiang, "Strategies for independent deployment and autonomous control of PV and battery units in islanded microgrids," IEEE Journal of Emerging and Selected Topics in Power Electronics, vol. 3, no. 3, pp. 742-755, Sept 2015.

[15] A. Sangwongwanich, Y. Yang, and F. Blaabjerg, "A cost-effective power ramp-rate control strategy for single-phase two-stage grid-connected photovoltaic systems," in 2016 IEEE Energy Conversion Congress and Exposition (ECCE), Sept 2016, pp. 1-7.

[16] D. Cormode, A. D. Cronin, W. Richardson, A. T. Lorenzo, A. E. Brooks, and D. N. DellaGiustina, "Comparing ramp rates from large and small PV systems, and selection of batteries for ramp rate control," in 2013 IEEE 39th Photovoltaic Specialists Conference (PVSC), June 2013, pp. $1805-1810$.

[17] W. A. Omran, M. Kazerani, and M. M. A. Salama, "Investigation of methods for reduction of power fluctuations generated from large grid-connected photovoltaic systems," IEEE Transactions on Energy Conversion, vol. 26, no. 1, pp. 318-327, March 2011.

[18] R. Yan and T. K. Saha, "Power ramp rate control for grid connected photovoltaic system," in 2010 Conference Proceedings IPEC, Oct 2010, pp. 83-88. 